\title{
How Nature and Culture
}

\section{Shape Our World}

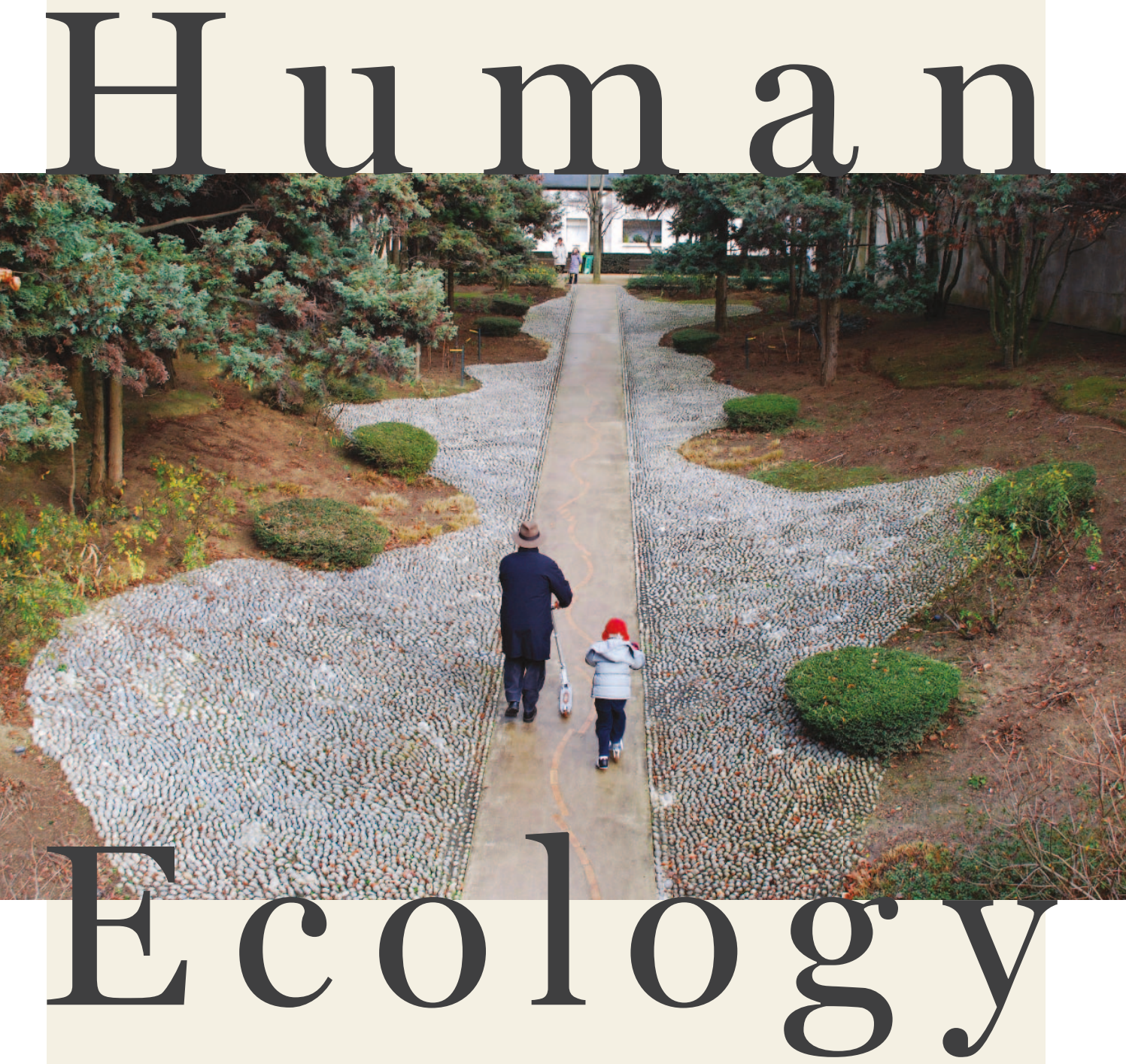

Foreword by Richard T. T. Forman 

HUMAN ECOLOGY 



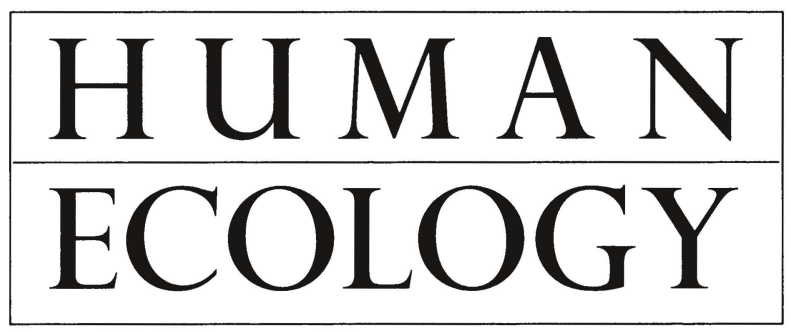

How Nature and Culture Shape Our World

FREDERICK STEINER

\section{Oislandpress}

Washington | Covelo | London 


\title{
Copyright @ 2016 Frederick Steiner
}

Originally published in 2002 under the title Human Ecology: Following Nature's Lead

\begin{abstract}
All rights reserved under International and Pan-American Copyright Conventions. No part of this book may be reproduced in any form or by any means without permission in writing from the publisher: Island Press, 2000 M St., NW, Suite 650, Washington, DC 20036
\end{abstract}

Island Press is a trademark of The Center for Resource Economics.

Library of Congress control Number: XXXXXXXXXXXXXX

Printed on recycled, acid-free paper

Manufactured in the United States of America

$\begin{array}{llllllllll}10 & 9 & 8 & 7 & 6 & 5 & 4 & 3 & 2 & 1\end{array}$

Keywords: adaptation, anthropology, architecture, biology, bioregion, biosphere, boundaries, climate change, community, conservation, connectivity, culture, diversity, ecology, economy, ecoregion, engineering, geography, habitat, landscape architecture, nature, regional planning, sustainability, water management 
What does it mean, anyway, to be an animal in human clothing?

$$
\begin{aligned}
& \text {-Barbara Kingsolver } \\
& \text { High Tide in Tucson }
\end{aligned}
$$

The story of man may be found in the palm of his hand, in the leaf of life impressed in his palm.

The cohesive force between molecules in a drop of water is the start of identity in our body.

-Giuseppe Penone

Giuseppe Penone 



\section{CONTENTS}

Foreword $x i$

Preface $x \mathrm{~V}$

INTRODUCTION: THE SUBVERSIVE SUBJECT 1

1. FUNDAMENTAL PRINCIPLES 19 OF HUMAN ECOLOGY

2. HABITAT 39

3. COMMUNITY 57

4. LANDSCAPE 77

5. THE ECOLOGICAL REGION 95

6. NATION, STATE, AND NATION-STATE 125

7. THE GREEN CHAOS OF THE PLANET 145

8. FOLLOWING NATURE'S LEAD 167

$$
\begin{gathered}
\text { Acknowledgments } 177 \\
\text { Notes } 181 \\
\text { Bibliography } 209 \\
\text { Index } 229
\end{gathered}
$$




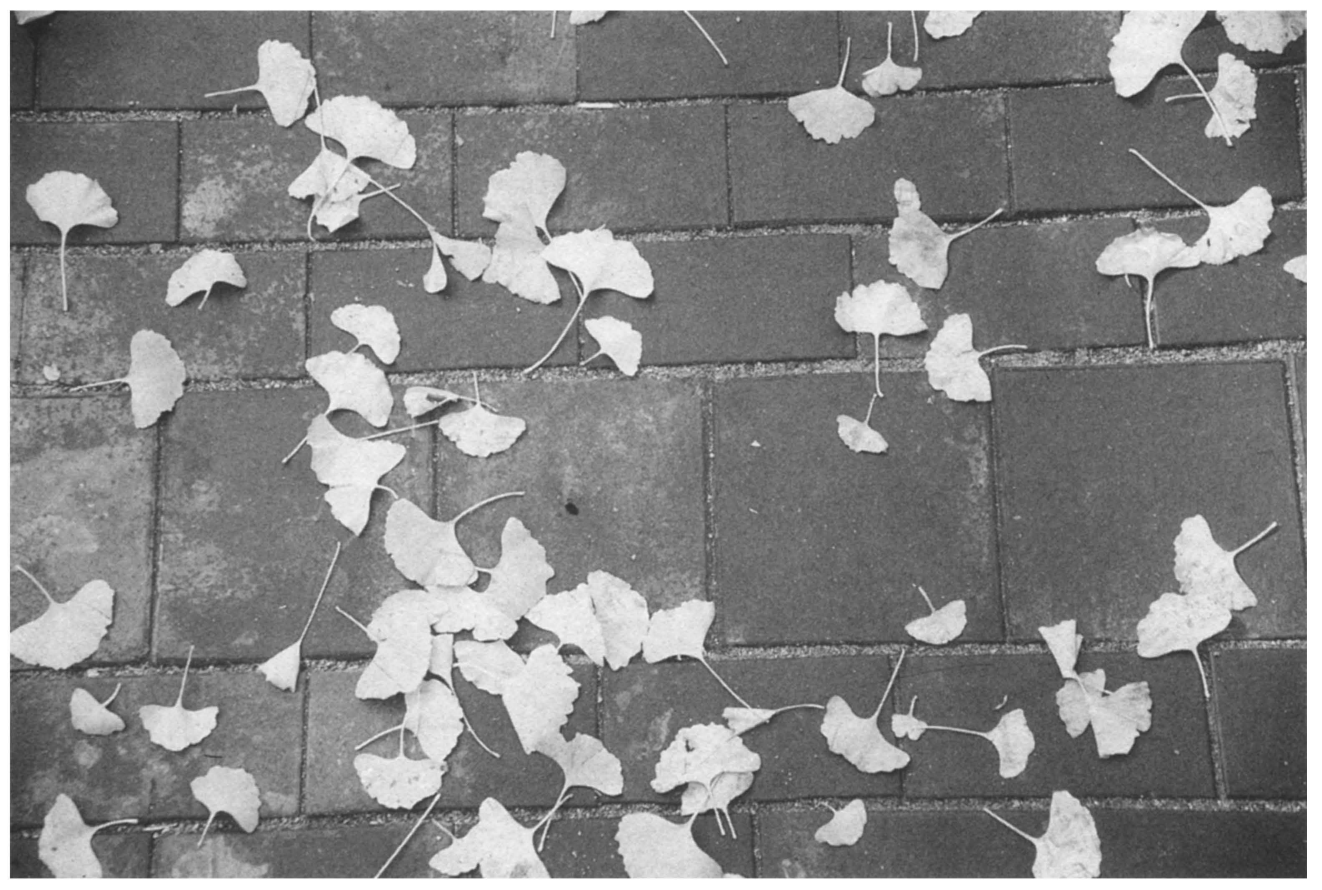




\section{FOREWORD}

The future? That's what lies ahead. Or is it what we create? Suppose nature and people were each working independently to mold the future. Or even imagine a future with human ecology at its core.

I recently heard of two prominent environmental leaders being separately asked by the press what they had accomplished in their careers. After a thoughtful pause each made essentially the same comment, "I believe I helped slow the rate of environmental (or land) degradation." The response was right on target. I was stunned by the answer. If leaders only slow the downward spirals so visible around us, there must be a more promising route.

Many of us spend our life trying to make the world we are given a little better. Yet an alternative exists that might accomplish far more. Try sketching out a vision, a goal for the future. Highlight its key principles and foundations. Give it tangible spatial outlines so that people can relate personally to it. Of course the vision will be partially shrouded. It will provide only glimpses upon which to construct a future. Over time, alternative visions, and the alternative trajectories to attain them, will emerge. Fine. Evaluating and choosing among visions and trajectories should be our bread and butter. People with vision get leaders and the public engaged.

Let me briefly illustrate. Consider a future where both nature and people thrive over the long term. To portray this vision, we accumulate state-of- 
our-knowledge principles and outline a framework or rough design that arranges nature and people to accomplish the core objective. This vision, as schematically portrayed below, first appears embryonic and shrouded, then slowly materializes. I see it as a ray of hope, a rare concrete basis for optimism.

Think of a large landscape bathed in swirling mist. We see only glimpses, vignettes. A few large blobs of natural vegetation. Strips of greenery along major streams. Connections between the large green blobs. Bits of nature scattered across a matrix of human activities and concentrated near the large green blobs. Major land uses mainly aggregated into large patches. Small sites of human activity concentrated along major land-use boundaries. Hermits, plus isolated human land uses, present but rare. Strategic points ringed by conspicuous planning and management activity. Road networks that facilitate walking and the natural movements of water and wildlife across the landscape. Traffic flows quiet enough for wildlife and people to thrive nearby. A coarse-grained land of large patches, but with fine-grained areas present. The overall framework or puzzle hierarchically organized yet tied together with loops, feedback loops.

Individual puzzle pieces also come into focus. Some exhibit natural processes; others, human activities; and many effectively mesh both. Buildings placed to avoid disturbing natural areas, and arranged for environmental and social benefits. Local and regional cultures manifest in the aesthetics and treasured heritage of places. Ecological flows and processes across the land little interrupted by human structures. Built areas with an abundance of natural forms and peppered with bio-rich spots. Buildings, routes, and green areas arranged for the daily uses in a person's home range. An imprint of walking routes and meeting places in built areas. Compatibility of adjacent puzzle pieces for both people and nature. Each patch sustained by links to a constellation of neighboring puzzle pieces.

This shrouded vision also hums right along and evolves over time. Water, soil, nutrients, and species moving, balanced by the flow of people, goods, money, and information. A changing landscape, not at the "overnight" rate of economics and politics, but sustainably at the rate of local and regional culture. Individual puzzle pieces transformed in harmony with broad keystone land-use patterns. These are but glimpses of a vision for a sustainable nature and people.

In contrast, the book in your hand provides substance and a welcome new perspective on human ecology. Frederick Steiner offers an impressive array of insights and vision. Every chapter bulges with principles and information. His syntheses provide new understanding but also address per- 
sistent societal challenges involving ecology and culture, nature and humans, land and people.

With foundations in anthropology, sociology, ecology, landscape architecture, and planning, human ecology not only plays an important role in each field but also increasingly manifests its own attributes. Two highlights very much on Steiner's palette-landscape ecology and landscape architecture/planning - add valuable new dimensions to human ecology. Combining a perceptive mind and a skilled hand, Steiner deftly unravels these fields. Furthermore, in concert with familiar human ecology perspectives, these new dimensions provide a solid yet creative foundation for action.

Delightful images appear throughout the pages ahead..Steiner leads us to discoveries in our own home and yard as well as in neighborhoods, cities, and the countryside. He opens our eyes to special places across the entire United States. The creative hands of Vitruvius, Jefferson, Penn, and Powell come alive. In a magical descent over Mexico City, he elucidates patterns spread out below. From Poland to Dubai, from Spain to Australia, and in every continent and in many eras, we take home vibrant human ecology messages. And imagine the proverbial cab ride across Rome: the perceptive author uncovers layer after delightful layer of insight into the intertwining arms of nature and people.

Steiner repeatedly poses important questions, many of which are the grist of discussion with family and friends, and others that are of a cosmic nature. Some are answered directly; many are addressed with salient principles and examples. Perhaps most make us ponder. In the hierarchy from home to globe, which level is most promising for a sustained human ecology? What would the human and the ecology components look like? Does regional planning have a chance? Do state departments of transportation create and eliminate communities? Is Gaia, ethics, or religion an essential cohesive force here? How can we best put our impressive knowledge of human ecology to work for society-and for nature?

With appealing prose, Frederick Steiner lucidly links science and art. The scholar, the student, and the educated public will learn much, and may experience an epiphany, in the pages that follow. Dig deeply; herein lies a treasure trove of wisdom.

RICHARD T. T. FORMAN

Harvard University 


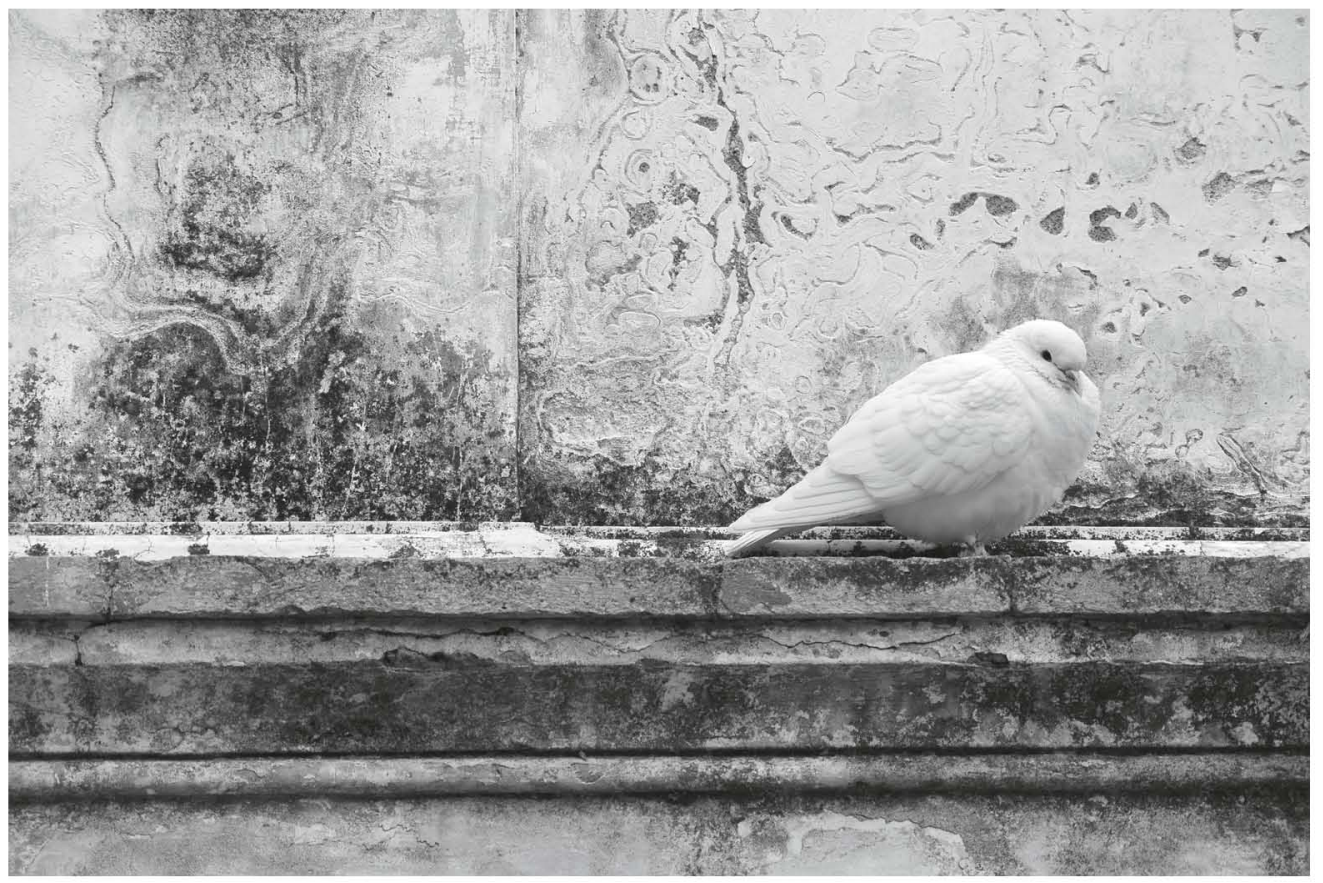




\section{PREFACE}

Two PROFOUND DEVELOPMENTS HAVE OCCURRED SINCE THE HARDcover edition of Human Ecology was first published in 2002 that amplify, the book's ideas. First, the world became mostly urban. For the first time in human history, the majority of people live in metropolitan regions. This: has far-reaching consequences for our species, and Human Ecology provides guidance for understanding people-environment interrelationships in urban settings.

Now, more than ever, we must ask ourselves: What does it mean to be an urban species? An urban animal? The global urban population is expected; to continue to grow. Whereas, in 1960 people living in cities accounted for 34 percent of the world's population, that had risen to 54 percent by 2014 and by 2050, according to the United Nations, it is expected to increase to 66 percent. Traditionally, urbanity was associated with civilization. To be; urban was to be civilized. However, an anti-urban bias also exists that associates cities with crime and disease. In any case, we are no longer hunters. or gatherers. Fewer people farm or ranch. The Industrial Revolution ended some time ago. Still, we are haunted by our cultural pasts. Texas, where I live, is an urban state but one with a country and western ethos. It is important to untangle the threads of past influence to plan the future. 
Second, since the book's initial publication, there have been considerable advancements in the emerging fields of urban ecology, ecosystem services, resilience, and regenerative design. As the planet has become more urban, many ecologists and other environmental scientists have focused their research on metropolitan regions. In the process, these researchers have acknowledged the obvious: people live in cities. The urban ecosystem is a human ecosystem. The National Science Foundation gave this research a significant boost in the United States when it established two urban Long Term Ecological Research (LTER) projects in Baltimore and Phoenix in 1997. These LTERs have since been on the forefront of integrating ecological and social research in urban ecosystems.

This research has contributed to a better understanding of ecosystem services which are benefits that we derive from the natural world, which we perceive as free and tend to take for granted. Bees pollinate, until they don't; seeds grow in the good earth, until they don't; we breathe clean air, until it's polluted; we enjoy the shade of an oak tree, until it's not there. The growing awareness of ecosystem services contributes to ideas concerning sustainability and, further, to resilience and regenerative design. Resiliency refers to the ability of a place to undergo disturbances by resisting damage and regenerating itself quickly and efficiently. Clearly, the ability for a system to sustain itself is an important resiliency factor. However, regeneration is even more valuable. Regeneration refers to processes that restore, renew, and revitalize their own sources of energy and materials. Sustainable planning and regenerative design require an understanding of human ecology, and are essential to mitigate and adapt to the consequences of climate change.

Finally, the timing of the paperback release for Human Ecology follows Pope Francis's compelling encyclical letter Laudato Si' published in May 2015, in which he explicitly addresses human ecology. In his clarion call for an integral ecology - an ecology of daily life - the pope states: "Given the interrelationship between living space and human behavior, those who design buildings, neighborhoods, public spaces, and cities ought to draw on the various disciplines which help us to understand people's thought processes, symbolic language, and ways of acting."

Human Ecology does just that, drawing on my perspective as someone deeply involved in designing communities, landscapes, cities, and regions. Furthermore, understanding human ecology through design enables people to better adapt to their environments, a necessary ability in this age of climate change. The insights provided by Human Ecology remain timely and 
relevant amidst the growing awareness that people are part of nature. Nature hasn't ended: it has enlarged. Human Ecology gives us timeless principles for following nature's lead, ultimately enabling us to create more noble environ-' ments for people and other species. 


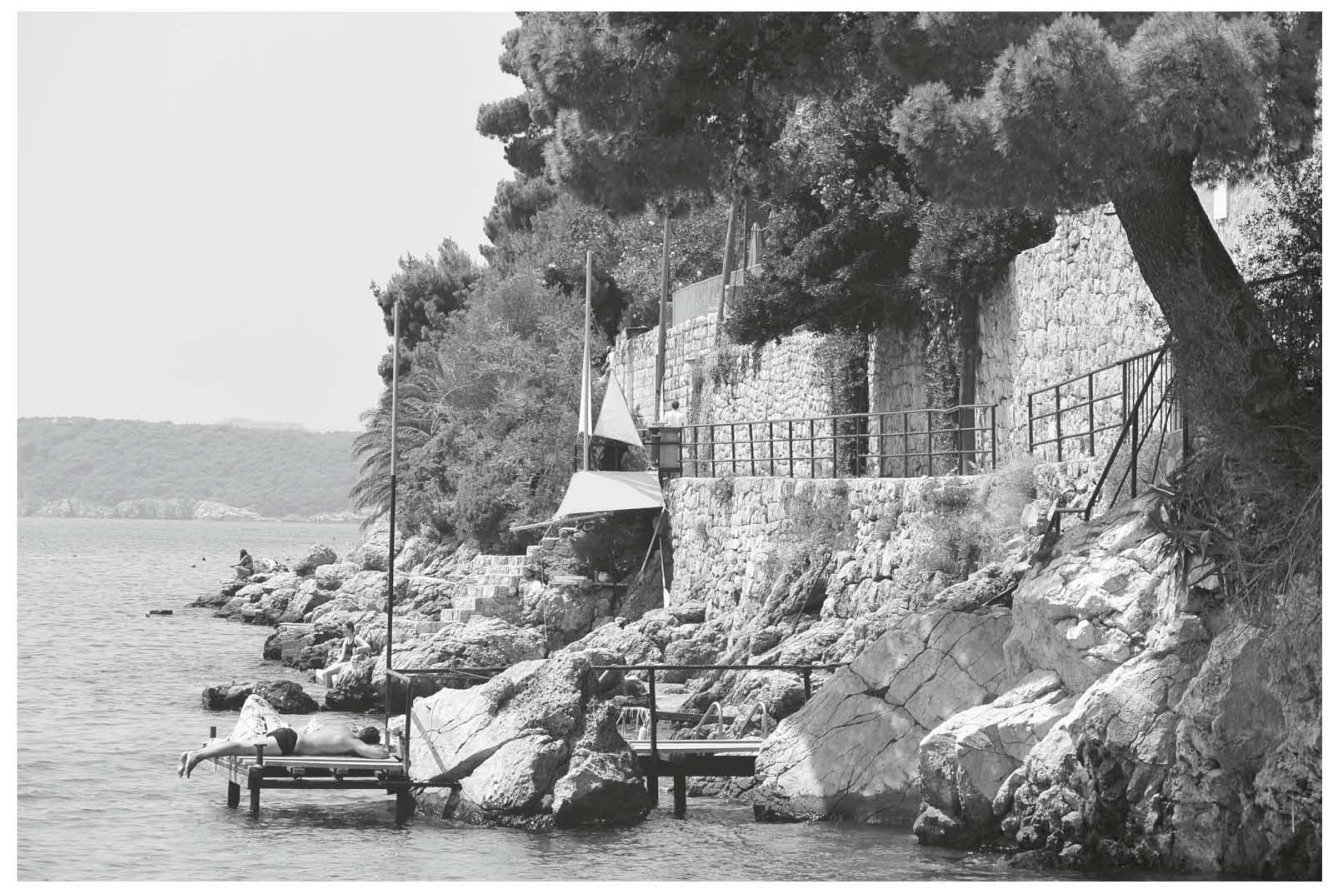

